\title{
Rethinking Earthquake Prediction
}

\author{
LynN R. Sykes, ${ }^{1}$ Bruce E. Shaw ${ }^{1}$ and Christopher H. Scholz ${ }^{1}$
}

\begin{abstract}
We re-examine and summarize what is now possible in predicting earthquakes, what might be accomplished (and hence might be possible in the next few decades) and what types of predictions appear to be inherently impossible based on our understanding of earthquakes as complex phenomena. We take predictions to involve a variety of time scales from seconds to a few decades. Earthquake warnings and their possible societal uses differ for those time scales. Earthquake prediction should not be equated solely with short-term prediction - those with time scales of hours to weeks - nor should it be assumed that only short-term warnings either are or might be useful to society. A variety of "consumers" or stakeholders are likely to take different mitigation measures in response to each type of prediction. A series of recent articles in scientific literature and the media claim that earthquakes cannot be predicted and that exceedingly high accuracy is needed for predictions to be of societal value. We dispute a number of their key assumptions and conclusions, including their claim that earthquakes represent a self-organized critical (SOC) phenomenon, implying a system maintained on the edge of chaotic behavior at all times. We think this is correct but only in an uninteresting way, that is on global or continental scales. The stresses in the regions surrounding the rupture zones of individual large earthquakes are reduced below a SOC state at the times of those events and remain so for long periods. As stresses are slowly re-established by tectonic loading, a region approaches a SOC state during the last part of the cycle of large earthquakes. The presence of that state can be regarded as a long-term precursor rather than as an impediment to prediction. We examine other natural processes such as volcanic eruptions, severe storms and climate change that, like earthquakes, are also examples of complex processes, each with its own predictable, possibly predictable and inherently unpredictable elements. That a natural system is complex does not mean that predictions are not possible for some spatial, temporal and size regimes. Long-term, and perhaps intermediate-term, predictions for large earthquakes appear to be possible for very active fault segments. Predicting large events more than one cycle into the future appears to be inherently difficult, if not impossible since much of the nonlinearity in the earthquake process occurs at or near the time of large events. Progress in earthquake science and prediction over the next few decades will require increased monitoring in several active areas.
\end{abstract}

Key words: Earthquakes, earthquake prediction, earthquake precursors, physics of earthquakes.

\section{Introduction}

National programs to predict earthquakes have been underway for more than 30 years in Japan, the former Soviet Union and China. Most work on prediction in the United States, however, did not commence until after 1978 with the establish-

\footnotetext{
${ }^{1}$ Lamont-Doherty Earth Observatory and Department of Earth and Environmental Sciences, Columbia University, Palisades NY 10964, USA. Fax: 914-365-8150; E-mail: sykes@1deo.columbia.edu
} 
ment and funding of the National Earthquake Hazards Reduction Program (NEHRP). In fact, earthquake prediction has been a relatively small component of NEHRP, which also includes funds for fundamental studies of earthquakes, earthquake engineering, estimates of risk to people and the built environment, insurance and various measures to reduce the loss of life and property in earthquake (all of which arguably belong in a well-balanced national program). Nevertheless, successes and failures of predictions worldwide and the recognition that the earthquake process is an example of a complex system dictate the need for a thorough review of what predictions are achievable now on various time scales, what might be accomplished in the next few decades, and what is likely to be inherently unknowable, i.e., unpredictable.

A number of recent articles, e.g., MAIN (1997), Geller et al. (1997), GELler (1997a-d) and Evans (1997), carry strongly worded titles like Long Odds on Prediction and Earthquakes Cannot be Predicted. They make claims regarding the earthquake process that we think are either incorrect or misleading. For example, articles like those of GELLER (1997a,b) and MAIN (1997), which were published as either opinion pieces in newspapers or short comments intended for more general scientific audiences, equate earthquake prediction with short-term prediction without stating so explicitly. Even for longer scientific articles in more specialized journals (e.g., Geller, 1997d; Geller et al., 1997) one must read well beyond the bold pronouncements of either the titles or abstracts to ascertain that by earthquake prediction they mean short-term prediction. All of the above articles argue that reliable short-term prediction, is inherently difficult if not impossible and that very high accuracy is needed for mitigation measures either to be taken or to be cost effective. The present extreme divergence of views relative to the feasibility of earthquake prediction and whether the study of earthquakes is, in fact, a science, are similar to those that existed about continental drift from 1920 to 1965. Many earth scientists, especially in the U.S. and U.K., do not regard prediction as "worth working on." Our paper is an attempt to challenge these views and to enlarge this debate.

The notion that several different kinds of prediction might be possible, each with its own time scale, is central to current debates about earthquake prediction. A short-term prediction of a few days to weeks, based on some earthquake process with a short time scale (e.g., nucleation), is distinct from a long-term prediction based on a longer-term process (e.g., stress buildup due to plate motions). These different kinds of predictions may have very different chances for success.

The public perception in many countries and, in fact, that of many earth scientists is that earthquake prediction means short-term prediction, a warning of hours to days. They typically equate a successful prediction with one that is $100 \%$ reliable. This is in the classical tradition of the oracle. Expectations and preparations to make a short-term prediction of a great earthquake in the Tokai region of Japan have this flavor. We ask instead are there any time, spatial and physical 
characteristics inherent in the earthquake process that might lead to other modes of prediction and what steps might be taken in response to such predictions to reduce losses? In this context we examine briefly what has been learned about the earthquake generation process, complexity and chaotic behavior, long-term prediction, and changes in rates of small and moderate-size earthquakes and in chemistry prior to large events. We argue that an important middle ground exists between very accurate predictions of hours to weeks and estimates of long-term seismic potential that are typically made for centuries or millennia.

\section{Terms for Expressing Earthquake Predictions and Potential}

We use four categories of earthquake prediction (long-term, intermediate-term, short-term and immediate alert) keyed to various warning times (Table 1). Each category has a known or inferred scientific basis (or bases) and some mitigation measures that might be taken to reduce loss of life and property. These categories and their associated warning times are similar to those advocated by WALLACE $e t$ al. (1984), except that we add the category immediate alert. All of these categories of prediction involve time windows that are shorter than the average repeat times of large earthquakes along a given fault segment or segments. They are examples of time-varying probabilities in contrast to estimates of long-term potential, which assume that large earthquakes occur randomly in time. We take 30 years to mark the transition from predictions to estimates of earthquake potential since time-varying probabilities probably have modest additional societal value for longer periods. From a tectonic viewpoint, however, the transition from one to another is better thought of as occurring at a certain fraction of the average repeat times of large shocks, which, of course, vary with long-term slip rates of faults.

We use the term "large earthquakes" very specifically to mean events that rupture the entire downdip width of the seismogenic zone of faults, the part of faults that is capable of building up stresses and releasing them suddenly (Fig. 1). Large shocks cause most of the cumulative damage and strong shaking worldwide. Also, our discussions are aimed mainly at very active faults - those of long-term slip rates of $10 \mathrm{~mm} /$ year or greater - where the repeat times of large earthquakes are typically decades to several hundred years.

\section{Complexity, Chaos and Predictability of Natural Systems}

Earthquakes, and the faults on which they occur, are thought to be an example of a complex physical system that exhibits chaotic behavior. Yet such a characterization does not preclude useful predictions. Many other natural hazards including floods, severe storms, wildfires, and climatic changes associated with El Niño also 
Table 1

Warning times, scientific bases, feasibility and mitigation measures for various types of earthquake predictions and estimates of long-term potential

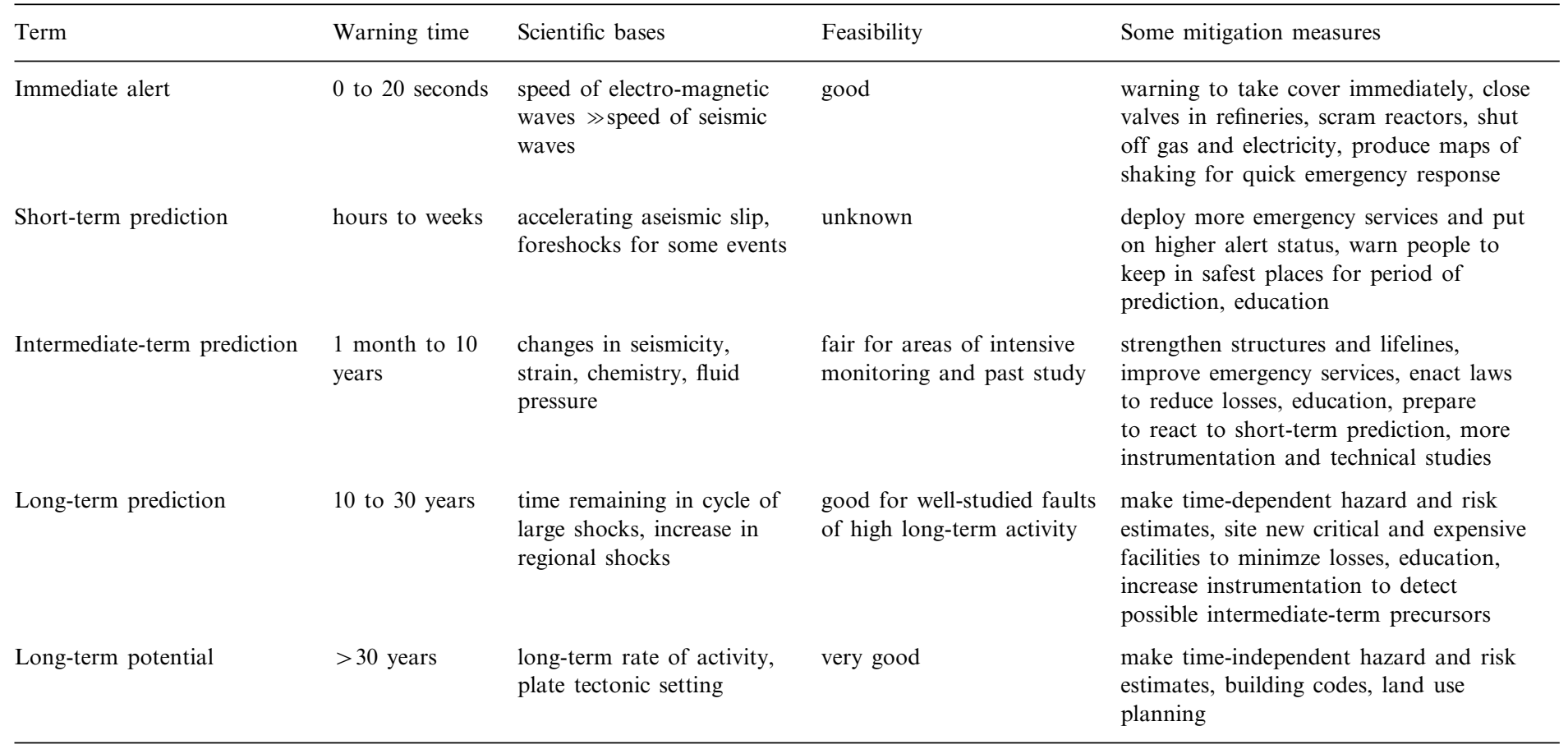


exhibit chaotic behavior. Weather, the classical example of chaotic behavior does have predictable elements. Atmospheric forecasts are made routinely for the next several days. The advent of satellite imagery greatly improved forecasts and warnings of hurricanes on a time scale of hours to days. Knowledge and monitoring of parameters affecting El Niño now furnish bases for making forecasts of departures from average climatic conditions for the following six months to two years. SHUKLA (1998) claims that wind and rain patterns in certain regions of the tropics are so strongly determined by the temperature of the underlying sea surface that they do not show sensitive dependence on the initial conditions of the atmosphere, as is the case for much of the earth's atmosphere. Nevertheless, the sensitive dependence on initial conditions for most of the atmospheric system indicates that accurate short-term predictions for specific dates, months and years ahead of time probably are impossible, e.g., whether it will rain on a given day in New York City a year from now or whether the temperature will be higher than normal on that date.

Volcanoes may also be a complex, chaotic system. Nevertheless, many volcanoes that have been active in the past 10,000 years cycle through decades to centuries of dormancy followed by months to years of activity of various types including increased strain, tilt, emission of gases, temperature and flow of water, shallow earthquakes and volcanic tremor. These increases can and have been used to make predictions on time scales of months to years that the chance of a damaging eruption is greater than in the long period of dormancy between major eruptions. Successful predictions on a time scale of days have been made, such as

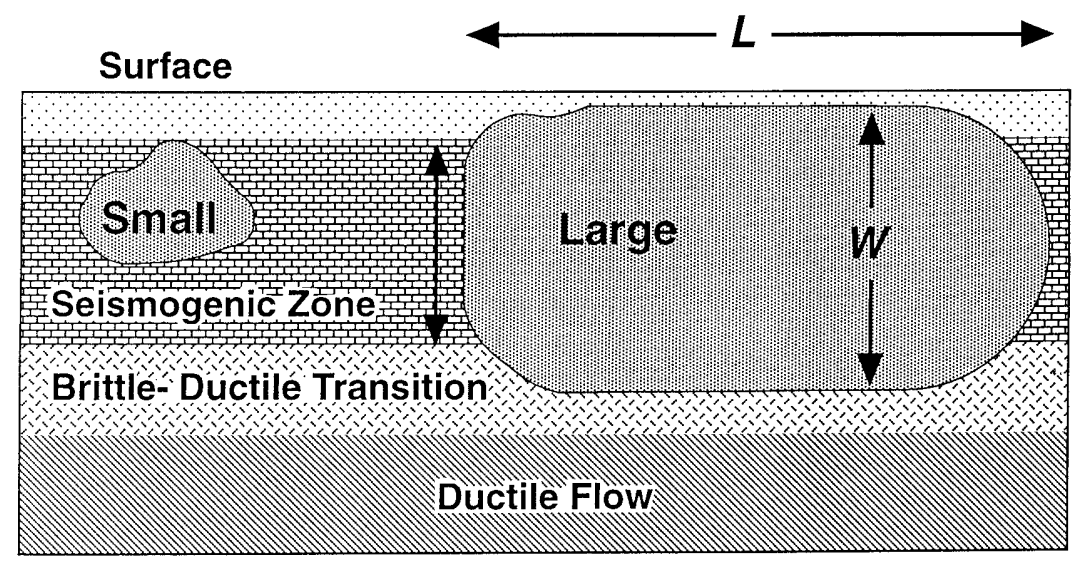

Figure 1

Two types of earthquakes - small and large, after PACHECO et al. (1992). $L$ is rupture length along strike of fault; $W$ is its downdip width. Small shocks do not rupture entire downdip width, $W$, that is capable of breaking in earthquakes, i.e., the seismogenic zone. Large events rupture entire downdip width, $W$. Small shocks are capable of growing in two dimensions, $L$ and $W$ whereas large earthquakes can become yet larger only by growing in one dimension, $L$. 
that for the major Pinatubo eruption of 1991 in the Philippines, on a short-enough time scale to permit evacuation and saving of many lives. Nevertheless, the duration and size of an eruption have proven difficult to ascertain in most cases. Monitoring is a key to greater understanding of the complex physics of volcanoes and to the prediction of eruptions on various time scales.

As with large earthquakes along a given fault segment, it appears to be inherently difficult, if not impossible, to predict beyond the next major eruption cycle into the future. Fortunately, prediction beyond one cycle into the future is of minimal societal value for either major volcanic eruptions or large earthquakes.

\section{Chaos and Determinism}

Chaos does not mean complete unpredictability or randomness, the common nonscientific usage of the word. It does mean that predictability eventually will be lost over long enough time scales. Key questions are the reasons for the complexity, the time scales over which predictability is lost and when do most nonlinear and complex changes occur during the cycle of large shocks along a given fault segment.

Earthquakes occur when stress exceeds the strength of a portion of a fault. During intervals between earthquakes, stress gradually increases as a result of plate tectonic loading. It is then suddenly released as the fault slips during an earthquake. The stress condition of a fault system is not uniform, but rather a complex distribution governed by the history of earthquakes, especially large earthquakes, on the fault system. We argue below that most of the complexity of the earthquake process arises from the sensitivity of the stress distribution to the details of the slip distributions in large earthquakes. Slight differences in the length of the rupture have a major effect on the subsequent state of stress of neighboring fault segments. The processes operating in the time intervals between large events, however, are usually far less complex. Thus, in the case of earthquakes, chaos and nonlinearity arise mainly during unstable sliding in large events. Even though small shocks are more numerous, large to great earthquakes account for most of the total slip that occurs in earthquakes as well as most of the seismic moment and energy release. It is mainly during large earthquakes that the system gets "stirred up" in a sensitive and complex way.

This point is illustrated using measurements from the simple "slider-block" physical model shown in Figure $2 \mathrm{a}$ which consists of a very long, one-dimensional elastic system of blocks dragged slowly at a constant rate. Motion of the blocks is resisted by friction along their bases. When friction weakens (decreases) sufficiently according to either slip or slip-rate relationships, a chaotic sequence of events ensues and one or more blocks slide. This is shown in Figure $2 b$ where we follow the manner in which two identical faults (such as the one shown in Fig. 2a) with nearly identical initial conditions at time $T=0$ differ as time progresses. Both faults evolve slowly at the same loading rate. Eventually an event occurs on one of them, 


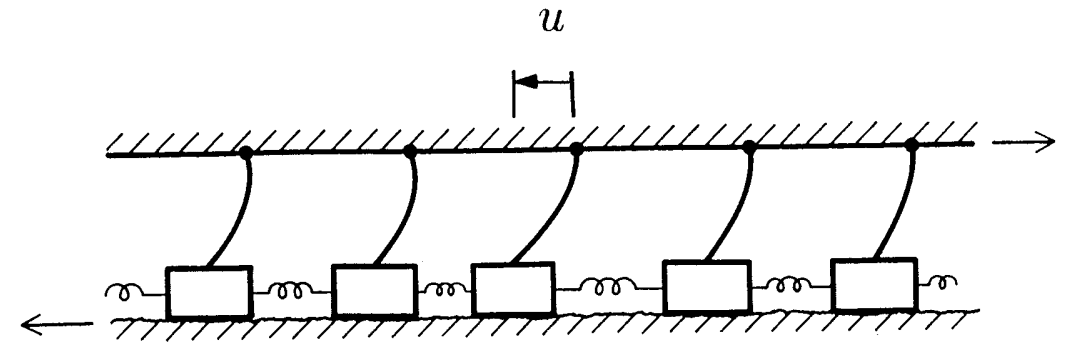

$x$

(a)

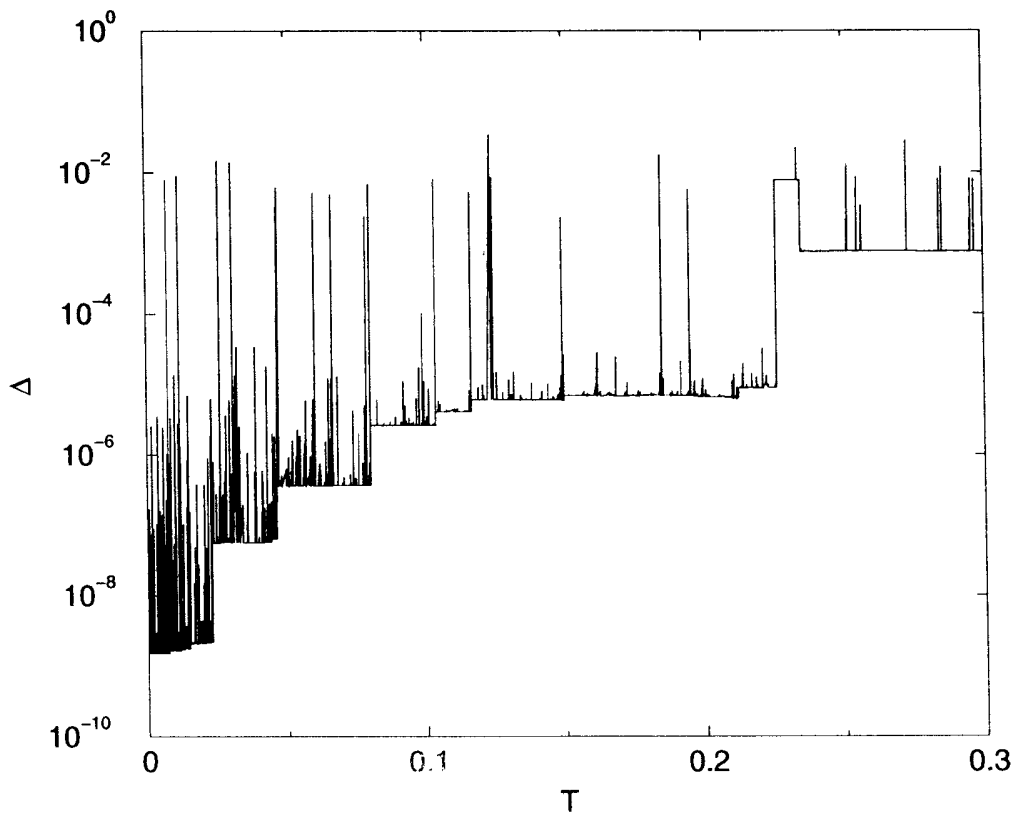

(b)

Figure 2

Chaotic behavior in a simple model of an earthquake fault. (a) Model consists of a very long, one-dimensional chain of blocks of equal mass. Each block is joined to its nearest neighbors by horizontal coupling springs of equal strength. Inclined pulling springs of equal strength attach blocks to upper plate, which is moving to the right at constant velocity. A frictional force that depends only on the slip history of blocks is present along contact between blocks and lower plate. (b) Chaotic behavior in two simple identical models of faults with nearly identical initial conditions is exhibited by exponential divergence as a function of time, $T$. Only a very small random initial difference between the two exists at $T=0$. Both faults are then loaded at the same rate and evolve separately. Vertical axis shows average of absolute value of the differences between the two faults as a function of time, $\Delta=\int\left|u(x)-u^{\prime}(x)\right| d x \mid$ $\int d x$, where $x$ is distance along each fault and $u$ and $u^{\prime}$ are the displacements along the first and second faults, respectively. Note that on this log-linear plot the log of the separation increases roughly in a linear fashion, showing on average, the exponential growth in $\Delta$ as a function of time for two faults with nearly identical initial configurations. 
and the differences between the two systems, $\Delta$ as defined in Figure 2, increase by the net slip of that event. Shortly thereafter, a corresponding event occurs on the other fault since its initial conditions were nearly identical to the first. Typically, the corresponding event will be similar to that on the first fault. Hence, $\Delta$, a measure of the difference between the two systems, returns to nearly its value before the two events. The events produce the spikes seen in Figure 2b. Occasionally, a corresponding event will be significantly different, leaving a residual difference or step in $\Delta$. Since the simulated faults are very long and we sum over their entire lengths, many large events (in which tens of blocks typically slide together) occur during the average repeat time, $T=1.0$, of a particular point on one of the faults.

Several important phenomena are illustrated in Figure 2b. First, most of the net increase $\Delta$ (i.e., when the spikes do not descend) occurs in large events (i.e., the largest spikes). Large events cause most of the divergence between the two systems. Second, the divergence grows roughly exponentially with time (since $\log \Delta$ increases approximately linearly with time). This exponential divergence is the hallmark of chaotic behavior. Third, the system is very sensitive to initial conditions; its state immediately after a large event is very sensitive to the details of the initial conditions.

Predicting slider-block events beyond the next large event is very difficult. Fortunately, in applying this finding to real earthquakes, that which we really care most about from a societal point of view is the approximate time and location of the next large shock. Here determinism is on our side. Given the dominance of large events in the model and of large earthquakes along a major fault, it is very important for long-term prediction to measure or deduce as accurately as possible the distribution of slip in large earthquakes. This distribution mainly sets the stage for the next large event(s). It is this that we choose to call "initial conditions" from a practical point of view since we have no hope of knowing detailed initial conditions thousands of years ago.

Far from being random, chaotic, complex systems are, in fact, highly correlated. Thus, despite that which will always be limitations in our knowledge of the distribution of slip in the last large earthquake and of the dynamics of the system, we can use the knowledge we now possess to make probabilistic statements concerning the future extending to the time of the next large event. While the uncertainty of these statements remains an open question, prediction, in this sense is possible.

\section{Uniformity and Complexity in the Earthquake Process}

Several aspects of the earthquake process indicate that it is less complex than most aspects of the circulation of the atmosphere. Unlike the atmosphere, which moves significantly even on short time scales, faults remain stationary over periods of tens of thousands of years. Faults do not change their configuration significantly 
even over several cycles of large events since the displacement in the largest shocks is at most meters to tens of meters. Relative plate motion, such as that between the North American and Pacific plates in California, is remarkably uniform on a time scale of years to a few million years. Complexity in the earthquake process results mainly from the following two effects: 1) from initial conditions resulting from the distribution of slip (and hence in stress drop) in the last large shock along a fault segment and 2) changes in stress along that segment produced by nearby large earthquakes. The second can delay or advance the timing of the next large event along the fault segment under consideration (DENG and SYKES, 1997). We have a reasonable chance, however, of being able to calculate those changes in stress generated by nearby shocks and hence to improve intermediate- and long-term predictions.

\section{Are Earthquakes a Self-organized Critical Process?}

In their classic paper on self-organized critical processes BAK et al. (1988) used the analogy of grains of sand being added slowly to a sandpile (Fig. 3). For large earthquakes, as for large avalanches on a sandpile, it is important to distinguish regional and global effects. Large sand avalanches can occur at various azimuths on the pile at any time (a "global" effect). Nevertheless, once a large slide occurs at a given azimuth on the sandpile (Fig. 3b) considerable time is needed to restore that segment to the angle of repose through the slow addition of grains from above such that a large avalanche can reoccur at the same place. In contrast, small avalanches (Fig. 3c) can occur at any time along a given azimuth since they affect only a small part of the slope at that azimuth.

Small earthquakes in a given region and large shocks globally manifest a similar behavior and follow the Gutenberg-Richter frequency $(N)$-magnitude $(M)$ relationship, $\log N=a-b M$, where the slope, or " $b$ value," is a constant of about 1.0. Large to great shocks along a major fault system are akin to large avalanches along a given azimuth of the sandpile (Fig. 3b). This effect can be seen in the pattern of earthquakes in the San Francisco Bay area. A broad neighboring area in which shear stress was lowered in the 1906 earthquake was very quiet for events of $M \geq 5$ for about 70 years after 1906 (e.g., SyKes and JAUMÉ, 1990). Shocks of that size were about 10 times more numerous from 1883 to 1906 . Thus, the greater San Francisco area can be regarded as at or close to a self-organized critical (SOC) state from 1883 to 1906 as manifested by the frequent occurrence of moderate to large earthquakes. This effect is illustrated for the sandpile in Figure 3d. Most of the greater San Francisco area was dropped below a SOC state for decades after 1906 akin to the azimuth of the sandpile in Figure $3 \mathrm{~b}$ that recently experienced a large avalanche. A portion of the area affected by the 1906 shock became more active for moderate-size events from 1978 until just before the Loma Prieta earthquake of 


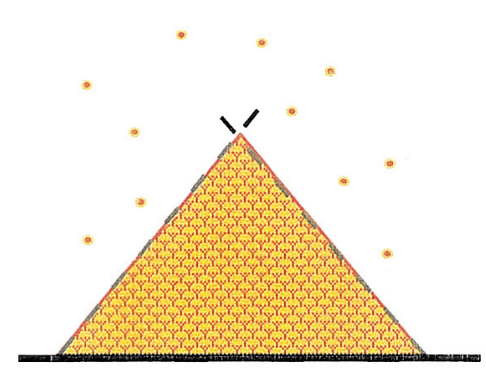

a

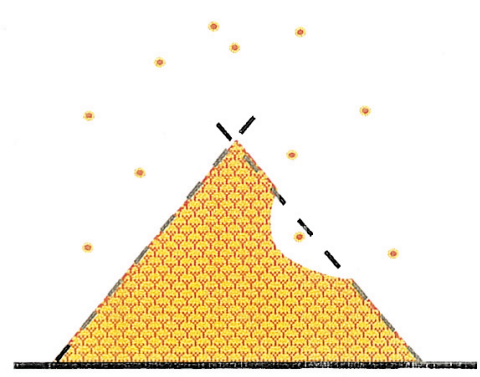

c

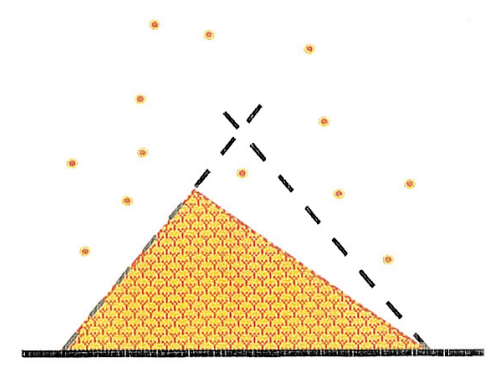

b

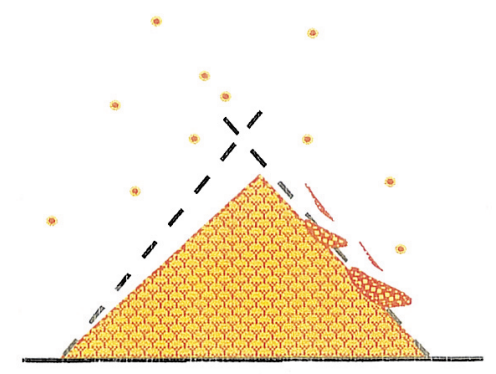

d

Figure 3

Grains of sand (small dots) being added slowly to a sandpile. (a) All sides of the sandpile have reached the angle of repose whereby additions of sand result in instabilities, i.e., avalanches, of various sizes. (b) A large avalanche has taken place along one small range of azimuths of pile taking that zone out of a self-organized critical state and making it incapable of being the site of a large avalanche for a long time (until grains of sand are added to it to bring its slope back to the angle of repose; large avalanches can still occur at any time along other azimuths. (c) A small avalanche occurs along one azimuth but does not affect its entire downdip slope; small avalanches can still occur along other portions of slope either up or downdip of that small avalanche. (d) Moderate-size avalanches occur as a given azimuth approaches or reaches a state of instability prior to a large avalanche. Large and small avalanches correspond to large and small earthquakes in Figure 1.

1989 (Sykes and Jaumé, 1990; JAumé and Sykes, 1996, 1999; Sykes, 1996). In fact, five years before the Loma Prieta earthquake SYKES and NiSHENKo (1984) proposed that the increase in regional moderate-size shocks from 1978 to 1983 may represent a long-term precursor to a large event on the nearby section of the San Andreas fault. The rate of moderate-size events in the greater San Francisco area returned to a low level from 1990 until the writing of this paper in early 1999 and hence may be regarded as out of a SOC state for large events, i.e., those of $M \geq 7$.

TRIEP and SYKES (1997) found that a large region of Asia to the north of the Himalayas was considerably more active for shocks of $M \geq 7$ in the decades before the giant $\left(M_{w}\right.$ 8.7) Assam earthquake of 1950 than in the decades since. The 
increased activity before 1950 and the fact that the $b$-value during that period remained about 1.0 even up to events of $M>8$ led them to conclude that the region was in a SOC state before 1950 and dropped out of that state in the following decades. The eventual return to a SOC state for a region that has been in such a stress "shadow" for many decades may be regarded as a long-term precursor.

Many critics of earthquake prediction argue that the constancy of the $b$ value, i.e., the slope of the log frequency-magnitude relationship, over a far-reaching range of sizes of earthquakes implies that no spatial or temporal scale exists for the earthquake process. The $b$ value does change, however, in going (Fig. 1) from small to large earthquakes (PACHECO et al., 1992; MAIN, 1996; TRIEP and SYKes, 1997). Most importantly, however, the Gutenberg-Richter relationship applies "in the large," i.e., either to the entire world or to regions larger than the size of the rupture zones of large earthquakes. It breaks down for fault segments comparable in size to the rupture zones of individual large earthquakes. The strongest evidence for this is that the observed rate of occurrence of large shocks along individual segments of fast-moving faults is considerably higher than the rate extrapolated from the occurrence of small shocks using the Gutenberg-Richter relationship with $\mathrm{a} b$ value of about 1.0. Hence, the often-repeated argument invoking the Gutenberg-Richter relationship as a justification for self-similarity among earthquakes, the existence of a SOC state at all times and places, and the lack of earthquake predictability is not correct at the scale of individual fault segments. Those arguments only apply to the less interesting case (at least for prediction) of earthquakes in a very large region such as the entire world, a continent or all of California.

\section{Is the Strain Buildup and Release Theory of Reid Still Valid?}

In his famous paper interpreting the geodetic data collected before and after the 1906 earthquake, REID (1910) proposed that the next 1906-type event in the San Francisco Bay area along the San Andreas fault would recur about the time that stress was restored to the level just before the 1906 shock. He proposed making geodetic measurements of deformation to ascertain that approximate time, i.e., to make a long-term prediction. His strain buildup/relief theory, as subsequently interpreted in a plate tectonic framework, is the basis of much of seismology including seismic gap theories and many long-term earthquake predictions. He assumed that stresses build up slowly, by what we now recognize as plate motion.

KAGAN and JACKSON (1991) challenge this view. They claim that once aftershocks are removed from consideration that clustering, not quasi-periodicity, characterizes the occurrence of all other earthquakes. Neither they, we, nor others, however, claim that large shocks occur strictly periodically along a given segment of an active fault. Rather, what is at issue is whether large shocks can recur soon 
after a previous large event along the same fault segment or whether a considerable waiting time is required for stresses to slowly re-accumulate.

In their study, KAGAN and JACKSON (1991), use data sets that consist largely of small events as defined by us in Figure 1. In their analysis of the global Harvard catalog of seismic moments of shallow earthquakes they take a lower cutoff magnitude, $M_{w}$, of 6.5 , claiming "these shocks are large enough to be plate-rupturing." A significant number of those events occurred at subduction zones. Their choice of $M 6.5$ as being a large event, i.e., one that breaks the entire seismogenic (downdip) width of a fault, is not correct since the transition from small to large events occurs at about $M 7.5$ for subduction zones and $M 7.0$ for many intracontinental regions (TrieP and SyKeS, 1997). Kagan and Jackson use an even lower cutoff, $M=1.5$, in their analysis of the Calnet (California) catalog.

Kagan and Jackson state correctly that quasi-periodic behavior would result in a deficit of pairs with short interval times. Statistical statements at high levels of confidence can rarely be made for the repeats of large shocks that rupture the same or a similar fault segment. Since the time intervals between such events is typically greater than 50 to 100 years, the number of known and well-described repeats of large shocks of that type is small. Probably the best sequence of this type, however, is the long record of historically great earthquakes along the Nankai trough of Japan. Those events are reasonably described as quasi-periodic; none have reruptured the same part of the plate boundary in a brief time (years to a few decades) compared to the average repeat time of about 100 to 200 years.

A relatively new set of data has become available on repeats of small shocks along parts of the San Andreas and Calaveras faults in California. Ellsworth (1995), Nadeau and McEvilly (1997) and Nadeau and Johnson (1998) use a correlation of waveforms from densely-spaced stations to demonstrate that families of repeating small events of similar magnitude occur along the same fault patches to within the accuracy of their relative locations, 3 to $30 \mathrm{~m}$. Events they examined were of magnitude 0.2 to 5 . Those of $M>3$ have calculated source dimensions larger than $100 \mathrm{~m}$, i.e., larger than the uncertainties in the relative locations of events in individual sequences. Thus, the events in each of those sequences ruptured the same or nearly the same fault patch. The events of $M<3$ have calculated source dimensions of about 1 to $10 \mathrm{~m}$. Nevertheless, the identified shocks in each of those sequences also probably break the same fault patch since creep, not earthquakes, account for a large amount of the plate motion along those fault segments, and the patches with earthquakes appear to be relatively isolated spatially.

The number of small earthquakes breaking each fault patch, up to 13, and the number of patches are large enough that various models of recurrence can be tested with high statistical confidence. Events associated with a given patch are usually of similar size and occur quasi-periodically in time. Thus, their temporal probability distributions are decidedly non-Poissonian, i.e., non-random. Events along the same fault patch do not recur without sufficient time for stress to re-accumulate. 
Temporal clustering does occur for patches in close proximity to one another where one event triggers the occurrence of a nearby earthquake soon thereafter. A similar clustering of adjacent events in time is well known for large shocks along major plate boundaries.

We think that the examples of clustering cited by KAGAN and JACKSON (1991) also involve nearby events, not those that rerupture the same or nearly the same fault segment. Thus, their study does not invalidate the strain buildup hypothesis of REID (1910). In contrast, the work on small repeating earthquakes strongly supports Reid's hypothesis as well as it indicates that events along the same fault segment often occur quasi-periodically. ROSENDAHL et al. (1994) find a similar behavior for large avalanches on an actual sandpile of the type illustrated in Figure 3 . These results suggest that long-term prediction has promise.

The rupture patterns of large shocks along many active plate boundaries often differ from one sequence to another. A single segment may rupture in one event while two or more segments may break together in a subsequent large earthquake. For example, the 1906 California earthquake ruptured about $430 \mathrm{~km}$ of the San Andreas fault. Only about $50 \mathrm{~km}$ of that zone near its southeastern end reruptured in 1989; two segments some 90-km long ruptured in 1838 (TUTTLE and SyKES, 1992). The next rupture of a fault segment or segments is controlled strongly by the distribution of slip (and stress drop) in the last large event(s). For example, the 1989 shock ruptured that portion of the 1906 fault break that experienced the smallest displacement in 1906. Thus, it was along that segment that stresses were restored the soonest to their pre-1906 level. That segment was widely recognized as more likely to rupture in the few decades after 1983 than segments to the north of San Francisco that experienced larger slip in 1906 (LindH, 1983; Sykes and Nishenko, 1984; Scholz, 1985; Sykes, 1996; Harris, 1998a,b). Hence, long-term predictions could be made for the next cycle of large shocks along the 1906 rupture zone once the distribution of slip in 1906 was ascertained approximately. Presumably, better knowledge of that distribution both in depth and along strike would have led to more accurate long-term or even intermediate-term predictions. Predicting more than one cycle ahead, however, appears to be inherently difficult, if not impossible, since considerable nonlinear behavior associated with a fault segment occurs at the time of large to great earthquakes.

\section{Time Scales and Physical Bases for Predictions}

Table 1 describes various types of earthquake predictions, their known or inferred scientific basis (or bases) and examples of some mitigation measures that might be taken for each. We also present our assessment of the feasibility in principle of being able to make various predictions, assuming that they apply to an active region which has been studied extensively and is well instrumented. To the 
extent possible, we endeavor to use physical understanding of various precursory effects in separating and defining the types and time scales of predictions. We strive to employ either knowledge (or inference) relative to what is now possible, what may be possible and what is likely to be inherently unknowable.

\section{Long-term Prediction}

We use 10 to 30 years as the warning time for long-term predictions and have in mind very active faults for which individual fault segments are characterized by average repeat times of about 50 to 300 years. Predictions of this type are based on knowledge of the average repeat time and variations in individual repeat times for each segment, the size of its last large shock and the time that has elapsed since it occurred. The physical bases for this type of prediction are the slow buildup of stress, the loading rate for each fault segment, and the timing of the warning interval with respect to the approximate time remaining in the cycle of large earthquakes. Predictions of this type are usually probabilistic in nature to allow for observed differences in individual repeat times and uncertainties in the parameters used in the calculations.

In the United States a consensus exists for 30-year predictions of this kind for very active faults of northern and southern California. Since the first US Government report of this type a decade ago (Working Group on CALIFORNIA EARTHQUAKE Probabilities, 1988), follow-up studies have been published for northern and southern California in 1990 and 1995, respectively. The fact that these are consensus documents and that they have been reviewed by governmental panels such as the National Earthquake Prediction Council and the California Earthquake Prediction Council appear to be major factors in their use and acceptance by the public, large corporations and several governmental organizations. It is clear that a variety of stakeholders (i.e., "customers") exists even for long-term predictions. A major electrical utility in California used the reports in selecting the site for a new multi-billion dollar generating facility. The results of the 1990 report for the greater San Francisco Bay area were featured in an insert in local newspapers focussing on earthquake risks and how citizens could prepare for the next large earthquake in the Bay area. Over a million copies of that insert were distributed. Responses to long-term predictions are likely to differ from those of the owner of a single-frame home to those of a corporation planning a major investment for a facility with a projected lifetime of decades.

The most successful long-term forecasts for large shocks in California were those for the Loma Prieta earthquake of 1989, which are summarized in HARRIS (1998a,b). Long-term predictions for either 20- or 30-year duration made in the 1980s for the next Parkfield earthquake do not expire until 2003 or later. Nevertheless, the intermediate-term prediction of BAKUN and LINDH (1985) that the next Parkfield earthquake would occur before 1993 was not correct. Two explanations have been 
put forward to explain that failure: 1) the 1934 and 1966 Parkfield events did not break the same segments of the San Andreas fault and 2) stresses, including perhaps fluid pressures, at Parkfield were perturbed significantly by the nearby Coalinga earthquake of 1983. Perhaps equally as successful as the Loma Prieta forecasts were predictions (Working Group on CAlifornia EarthQuake Probabilities, 1988) that certain segments of the San Andreas fault, such as that to the north of San Francisco where slip in 1906 was high and the Carrizo segment where slip was as great as $9 \mathrm{~m}$ in the great shock of 1857 , had a low probability of rupturing in large events in the subsequent 30 years. Large shocks have not occurred along any of the segments assigned a low probability in the 1988 document.

The accuracy of long-term predictions probably can be improved through better knowledge of initial conditions, i.e., slip in the last large shock and better modeling of fault interactions. We think that it is unlikely, however, that forecasts based on these types of data can be improved to better than about $10 \%$ of the average repeat time of large shocks along a given fault segment. Nevertheless, that would be about 8 years for the Loma Prieta segment of the San Andreas fault. It would be longer, of course, for faults with lower long-term slip rates.

\section{Seismic Gap Theory}

A crude form of long-term prediction used in the absence of quantitative data called seismic gap theory simply states that large events along a specific plate boundary segment will be widely separated in time. We do not want to suggest, however, that seismic gap theory is more advanced than a first, primitive step towards prediction. Most work on seismic gap theory was published before 1982 . Considerable subsequent work (e.g., Sykes and Nishenko, 1984) has focused on making time-varying probabilistic predictions for fault segments along the main plate boundary in California, offshore western Canada, southern Alaska and the Aleutians. Those calculations took into account the rate of loading for each fault segment, the size and date of its last large event, its average repeat time and their standard deviation, which simple seismic gap theory does not. Many of the newer calculations not only were more quantitative but also they took into account pronounced gradients in slip in great earthquakes, such as from about 2 to $6 \mathrm{~m}$ along the rupture zone of the 1906 California shock, which gap theory could not. The application of simple gap theory in about 1981 merely yielded the result that the entire 1906 zone had not ruptured in many decades. LindH (1983) and SYKES and NisHENKo (1984) proposed that reloading had brought stresses along the southeastern end of the 1906 rupture zone close to their pre-1906 levels whereas stresses along segments to the north of San Francisco where slip was highest in 1906 were still far below their pre-1906 levels. Similarly, that portion of the rupture zone of the 1968 Tokachi-oki earthquake where slip was smallest in 1968 broke in the great thrust earthquake of December 1994 (TANIOKA et al., 1996). Thus, we 
conclude that time-varying, long-term probabilistic predictions that include information treating pronounced gradients in slip in the last great earthquake represent an advance with respect to simple gap theory. The accuracy of the newer probabilistic methods, however, does require more information about initial conditions, such as the distribution of slip in the last large shock, particularly for great events that rupture several fault segments.

\section{Intermediate-term Prediction}

We take the warning time for this type of prediction to be one month to ten years. Changes in chemistry, fluid pressure, seismicity and strain have been observed which have time scales of this period.

The rate of occurrence of moderate-size events along nearby faults is known to have increased in the last 5 to 25 years of the seismic cycle of numerous large to great earthquakes (Sykes and JAumé, 1990; JAumé and Sykes, 1996, 1999; TrieP and SYKES, 1997). By our definitions these changes include both long- and intermediate-term precursors. The physical mechanism of these increases in seismicity appears to be the return of stresses to levels that existed prior to the last large to great shock in the neighborhood of the fault segment under consideration. If so, the warning time is expected to scale with the average repeat time for that fault segment. Simple computer simulations of earthquakes along a one-dimensional fault show increased organization and an increase in the frequency of moderate-size events prior to the occurrence of large to great events (PEPKE et al., 1994).

Two earthquakes near Lake Elsman, California, of about $M 5.3$ occurred in the 1.5 years before the 1989 shock. The Loma Prieta segment and the adjacent Peninsular segment of the San Andreas fault to the northwest were characterized by very low levels of activity of that size in the 70 years after the 1906 earthquake. The Lake Elsman shocks were interpreted by some as being on the San Andreas fault and hence as possible foreshocks to a larger event. In retrospect we now understand that they occurred on a nearby subparallel fault to the one that ruptured in 1989. Hence, they neither reflected the nucleation of slip on the 1989 rupture zone itself nor were they short-term precursors. Instead, they more likely represent an intermediate-term precursor that reflects the return of stresses to pre-1906 levels close to the fault segment that ruptured in 1989. While their number was small, their occurrence led to increased anxiety among a number of earth scientists about an approaching larger shock. Better knowledge of fault geometries on a scale of kilometers and of which of those faults are either likely or unlikely to produce large earthquakes could help distinguish moderate-size events that occur on nearby faults, and hence are not likely to represent nucleation of rupture in a large event, from those that are located on the main fault itself (SYKES, 1996). The occurrence of moderate-size events of this type may provide a means to improve intermediate-term predictions 
at the year to decade level for places where precise locations of events are possible. A capability to locate earthquakes at the kilometer or better level so as to distinguish one nearby fault from another does not exist for the shallow plate boundaries at subduction zones.

The Joshua Tree earthquake of April 1992 occurred close to the southernmost portion of the San Andreas fault, a segment that has not ruptured in a large to great event in about 300 years. Its occurrence led to the issuance of a short-term warning for a larger nearby shock in the next few days. Such an event did not occur during that time frame. Aftershocks, however, did migrate northward in the next two months to near the epicenter of the large Landers earthquake of $M$ 7.2. Thus, in retrospect, the Joshua Tree sequence appears to have been causally related to the coming Landers event and may be regarded as an intermediate-term precursor.

Wyss and his colleagues (e.g., Wyss et al., 1996) report precursory quiescence for small earthquakes along parts of the coming rupture zones of many large earthquakes. These reports of quiescence are not in conflict with increased levels of moderate-size shocks before large earthquakes since reports of quiescence are associated with small shocks along the rupture zones of coming large events while the latter involve moderate-size events in a considerably larger neighboring area. The time scales of quiescence are about 0.5 to 3 years and hence are intermediateterm precursors by our definition. The physical mechanism of quiescence probably differs from that controlling the increased frequency of moderate-size regional events. Quiescence of this type may reflect either dilatancy hardening of materials along parts of a fault zone or slip weakening late in the seismic cycle (SCHOLZ, 1988, Main and Meredith, 1991).

Chemical changes in ground water have been monitored at numerous sites in Japan for up to 20 years. An anomalous change in radon in the few months before the 1978 Izu-Oshima earthquake and in the concentration of chloride and in sulfate ions in the five months before the 1995 Kobe earthquake (TsUNOGAI and WAKITA, 1995; WAKITA, 1996) are two of the clearest examples of precursory changes in chemistry. Changes in radon and in water level have been observed in some wells in Japan and California although not in others (WAKITA, 1996; ROELOFFs and QuiLTY, 1997). It is clear, however, that some wells are more responsive to earth tidal stresses and changes in barometric pressure than others, which may explain the presence of precursory signals at some but not other nearby wells (ROELOFFS and QuiLTY, 1997). Anomalous changes in earth strain in the months before some large earthquakes generally have been reported at single observation points, which is to be expected given their sparse deployment. For geochemical, hydrological and strain changes to be accepted widely as precursors by the scientific community, multiple observations for individual earthquakes are needed. To "catch" multiple examples of changes in one or more parameters will require a substantially greater concentration of observations than presently exist except in a few places. In the United States such a concentration of observations exists only at Parkfield. To our knowledge, however, changes in chemistry are not being monitored there. 
We think the prospects for intermediate-term prediction are better than for short-term prediction. A prediction of five years would permit a number of measures to be taken that would not be possible for short-term predictions alone. These include strengthening of critical structures and lifelines, stockpiling more emergency supplies, improving emergency response and conducting disaster drills (SYKES, 1996). Predictions of that type are not possible today but might be possible in about twenty years if programs to investigate intermediate-term precursors were pursued actively. Undertaking serious mitigation measures would require a scientific and technical consensus about intermediate-term prediction of the type that exists today for long-term predictions in California. Such warnings need not be at a confidence level greater than say $95 \%$ for at least certain mitigation measures to be undertaken; however, they probably would need to be at a level higher than $50 \%$ for many potential "users" of those warnings to do so.

\section{Short-term Prediction}

Long-term and intermediate-term predictions will not satisfy everyone as being "real" earthquake predictions. Can we do any better? Is short-term prediction with a lead time of weeks or hours impossible as a number of authors contend? This issue does not depend on the SOC nature of seismicity. It depends on whether or not there is a precursory phase of the earthquake instability that can be detected confidently with instruments. Frictional instability theory indicates that the stickslip instability that results in earthquakes must be preceded by an aseismic nucleation stage (e.g., DieTERICH and Kilgore, 1996). Its likely existence means that short-term prediction is possible in principle but we don't know whether or not it can be accomplished in practice.

The most commonly observed phenomena that are a likely manifestation of this nucleation process are foreshocks. This is simply a result of the fact that the only continuously recording instruments that are widely deployed are seismometers and their effective pass band is limited to periods less than one hour. Nucleation, however, is inherently an aseismic process to which foreshocks typically are incidental. For many large earthquakes, foreshocks are either absent or of very small size, making them unreliable for prediction purposes. Hence, the question of whether short-term prediction is possible depends on whether or not a means can be devised to detect nucleation directly, and if the form of the nucleation is predictive of the size as well as the time and the place of the subsequent event. These are questions to which we do not know the answers. The size of the nucleation phase of large earthquakes is hotly debated (e.g., ABERCROMBIE et al., 1995; DoDGE et al., 1996) and, we think, unresolved. Its depth of occurrence and

dimensions probably will determine whether short-term precursors can be detected or not. 
Strain measurements give the best signal-to-noise ratio for earth deformations with periods from about an hour to months. It is in this period range that slow nucleation of rupture is likely to occur. GPS is usually superior for longer periods and seismometers for shorter periods. We think that greater emphasis needs to be given to the detection and study of aseismic nucleation, not foreshocks, for short-term prediction. State-of-the-art strain measurements are not being made with sufficient density except in a few places.

It is often stated that it is not possible to ascertain if a magnitude say 2 or 4 earthquake will be the particular small event that develops into a large event. During the early and middle part of the cycle of stress buildup to large events, however, a small event along a fault segment is unlikely to grow into a large earthquake along the same segment. Even in the later part of the cycle of stress buildup, it may be that it is only small shocks in certain locations, such as near a large asperity, that have the possibility of either being foreshocks or continuing their rupture process to become large events.

Unlike intermediate-term predictions, insufficient time is available in response to short-term predictions to take many mitigation measures, such as retrofitting buildings and lifelines (SYKES, 1996). The complexities of the nucleation phase of rupture in large events are likely to make short-term prediction approximately 100 days in advance inherently impossible.

\section{Immediate Alert}

Seismic waves, especially more damaging shear and surface waves, travel at wave velocities considerably less than the speed of electromagnetic waves. Several urban areas in California and elsewhere are located 50 to $150 \mathrm{~km}$ from faults that are capable of generating large to great earthquakes. Warning times of seconds to tens of seconds are possible if information pertaining to strong shaking close to the rupture zones of large shocks is detected, transmitted to an analysis center and used to generate an immediate warning of impending strong shaking in adjacent areas. Such a system is under development in southern California (KANAMORI et al., 1997). It will be used first to rapidly ascertain the locations of strong shaking in future large events and to infer likely or possible levels of damage and loss of life. These will greatly aid rapid emergency response, something that is often delayed many hours (and sometimes days) as a result of inferior information on the loci of strong shaking, damage, injury and loss of life.

Such systems also could be used for immediate alerts that could permit the shutting down of critical valves in refineries, the insertion of control rods in nuclear reactors, the stoppage or slowdown of trains, and other measures that could be implemented in seconds to tens of seconds. These types of mitigation measures would need to be preplanned and initiated nearly automatically. Issuing immediate alerts appears to be doable in principle but must be developed and tested. While an 
immediate alert would not be useful for a city very close to the rupture zone of a large earthquake, nevertheless, sensors still could provide for rapid assessment of the disaster and rapid emergency response.

\section{Responses to Earthquake Warnings}

Many of the recent critics of earthquake prediction argue that high reliability is a prerequisite for engaging in [short-term] prediction. MAIN (1997) states "otherwise a programmed evacuation could not take place." GELLER et al. (1997) state that predictions need to be reliable, accurate and short-term "to justify the cost of response." Many scientists equate prediction with short-term prediction in the erroneous belief that only it can result in significant mitigation of either damage or loss of life. Others argue that short-term prediction is the public's desire or expectation.

We agree that evacuation of population centers is an extreme measure that should only be undertaken when the threat is dire and the benefits outweigh the costs. The Los Angeles area, however, could not be evacuated in hours and probably not in a few days. Even given a perfectly reliable short-term prediction, deaths and injuries resulting from an attempt to evacuate the region would likely surpass those resulting from the earthquake itself. Many things can be done in response to short-term earthquake warnings that are far less drastic than evacuating cities. Considerable literature exists in the social sciences addressing various responses to hazard warnings.

In the United States forecasts of natural hazards such as those for severe storms are made in more than one category. For example, a "hurricane watch" is a forecast of lower probability than a "hurricane warning." Those engaged in emergency response, governmental officials and the public generally respond differently to those two types of forecasts. If applied to weather forecasting, the high accuracy demanded by GELLER et al. (1997), MAIN (1997) and others would preclude many one- to four-day forecasts and would result in the omission of lower-level warnings for severe storms.

Many different users or potential users exist for warnings of natural hazards. There is no single user of hazard warnings, i.e., a generalized "public," but rather many different stakeholders or "customers," each with different assets at risk and different "costs" associated with taking measures to reduce loss of property and/or life. For example, NASA moved a multi-billion dollar space shuttle from its launching pad back into its assembly building in response to a watch issued for hurricane Georges in 1998. Others merely waited to see if the watch would be either cancelled or upgraded to a hurricane warning.

Scientifically-based predictions for many natural hazards are likely to be probabilistic statements. The U.S. public has, in fact, become accustomed to forecasts 
that give the probability of rain tomorrow or a few days from now. Past claims that the public cannot understand or deal with probability no longer seem valid.

We urge earth scientists to take the lead in educating one another and the public about that which can be accomplished now, what might be accomplished in the next few decades and what may well remain unknowable for various time scales. We may not be able to deliver on highly-accurate short-term predictions. Nevertheless, our inability to produce the spectacular should not prevent us from engaging in mitigation measures that are more modest, and to be proud of those accomplishments. Clearly, debate is needed relative to the benefits and costs of predictions of various reliability and for those of different warning times.

\section{Summary}

We assert that earthquake prediction involves several different time scales: immediate (a few to tens of seconds), short-term (hours, days, weeks), intermediateterm (one month to one decade) and long-term (10 to 30 years). Precursors or possible precursors in each of these categories appear to have different scientific bases. We emphasize that which is possible now (long-term prediction in a few well-studied areas), what might be achievable in a few decades given a vigorous program of monitoring and study (intermediate-term predictions on a time scale of several years to a decade) and what now appears to be inherently impossible (predictions of large shocks more than a cycle in advance or of short-term predictions of events far into the future). While earthquakes are the culmination of complex physical processes, that does not mean that predictions of all types are impossible. We argue that a variety of responses is possible for predictions of various warning times which occupy a middle ground between doing nothing and evacuating cities. In addition, a variety of potential users (i.e., consumers or stakeholders) exist for prediction information. Each has different assets (including possibly their lives) at risk for different warning times. The mitigation measures they may take are likely to vary.

GELLER et al. (1997) claim that "the obvious ideas [in prediction] have been tried and rejected for over 100 years." In fact, only a few individual earth scientists, like Imamura in Japan, worked seriously on prediction prior to 1965 . Nearly all work regarding prediction worldwide has been carried out during the last 30 years. Reid's proposal in 1910 for long-term prediction based on geodetic measurements was not instituted in the United States for more than 60 years. Parkfield is the only area in the U.S. monitored by a dense array of sensors which measure a variety of physical and hydrological parameters. This is despite the recommendation in 1965 by a Presidential panel for similar arrays and a multiplicity of types of measurements along major faults in California, Alaska and the Aleutians to better understand the earthquake process and to record possible precursors to earthquakes. The 
U.S. National Earthquake Prediction Evaluation Council (NEPEC) warned in 1986 of the danger of "putting all of the U.S. eggs in the Parkfield basket" and recommended intense monitoring of about 10 segments of very active, major faults in California and Alaska. Recently, this was done in part for the Hayward fault but for no others recommended in 1986. Unless dense monitoring of a variety of physical and chemical parameters is undertaken in many other areas in the U.S. the chance of "catching" a large event and its possible precursors in the next twenty years is unlikely.

Considerable progress has been made in the last 20 to 30 years in understanding the earthquake process, including the plate tectonic bases of earthquakes, the nature of frictional processes, precursory slip in the lab and the possible role of fluids at depth in fault zones as well as in determining rates of strain buildup using GPS and other instruments, developing geological techniques to detect large paleoseismic (pre-historic) events, determining long-term rates of fault movement, modeling the evolution of stresses in California, developing instruments that have detected so-called slow earthquakes, discovering guided waves along fault zones, detecting quiescence of small shocks in the immediate vicinity of coming large earthquakes and delineating increased rates of moderate-size shocks in larger neighboring regions before large earthquakes. Long-term (30 year) forecasts have become accepted by many in the scientific and policy communities for many faults in California. Much remains to be done, however, in understanding the earthquake rupture process itself, detecting the nucleation of slow slip at depth along faults and other slow changes in deformation, detecting temporal changes in fluid pressure at depth in fault zones, and ascertaining why some subduction zones experience shocks as large as $M_{w} 9$ while others lack historic earthquakes larger than $M_{w} 7$.

We do not claim that earthquake prediction is easy; the subject is still in its infancy for all time scales. GELLER et al. (1997) state that the scientific question of whether prediction is either inherently impossible or just fiendishly difficult can be addressed using a Bayesian approach. They claim that each failed attempt at prediction lowers the a priori probability for the next attempts. The recent proof of Fermat's Last Theorem after hundreds of years of failed attempts is an interesting counter-proof. Geller et al.'s argument might hold more weight if nothing of significance had been learned in the meantime (or the learning curve is negative). But we think significant progress in understanding earthquakes has been made in recent decades. We would agree that many reported precursors that have been identified retrospectively are a product of either environmental noise or low signal-to-noise ratio. We do not, however, put all precursory observations in those two categories.

We favor a stepped approach that starts with estimating long-term potential and then moves to probability-based long-term prediction and thence to intermediateterm predictions. In most cases attempts to make a more specific prediction should be reserved for those fault segments that are identified as having moderate to high 
probability in the less specific category of warning. Resources will always be scarce enough that choices must be made carefully about fault segments to receive increased levels of funding for monitoring and studies. That is best done by progressively increasing investments as a fault segment is categorized as being likely to rupture in a large shock with increasingly shorter warning times. Thus, we think it is a mistake to jump from long-term to short-term prediction without attempting intermediate-term prediction. We sense that little attention is being given to intermediate-term prediction in the United States.

Of the various categories of predictions that we consider in Table 1, we know the least about the feasibility of short-term prediction. Whether it will be feasible depends on the nature and scale of the aseismic nucleation phase of large earthquakes. In addition to some of the possible mitigation measures that we list in Table 1, increased education concerning pre-event response options will be needed at each stage of prediction for it to be even potentially useful to various "consumers" of that knowledge.

We stress the need to determine the distribution of slip in large to great earthquakes along given fault segments as accurately as possible. It is these "initial conditions" as well as the effect of nearby large shocks on the distribution of stress that set the stage for the occurrence of the next large event along that segment. Monitoring networks and studies to determine that distribution of slip may well need to be tailored differently for areas of complex transpressional fault bends, such as those in California near Loma Prieta and San Gorgonio Pass, than for relatively straight fault segments. It is this legacy of accurate determinations of slip in the last large events that we can pass on to future generations so that they can better estimate the timing, location and size of future earthquakes in those areas.

While it is desirable to understand the physics of the earthquake process, it should be remembered that viable mechanisms of continental drift were not proposed until decades after data supporting drift became available. Hence, certain types of predictions may become not only possible but accepted before their full physical and/or chemical bases are established.

Some earthquakes are likely to be more predictable than others. The Haicheng earthquake in northeastern China in 1975 is an example of an event with regional long-term anomalies, which led to increased monitoring, followed by a well-defined foreshock sequence and the issuance of a short-term warning. Large earthquakes which involve thrust faulting at subduction zones may be more difficult to predict on time scales shorter than about 10 years since slip typically starts at a depth of some $50 \mathrm{~km}$, considerably deeper than along transform faults and faults in other continental settings. Monitoring of thrust faults at subduction zones is usually more difficult since those zones are largely located at sea. Predictions for specific time intervals are likely to be more difficult for faults with low long-term slip rates, especially those in intraplate areas. 
We are concerned that earthquake prediction is not regarded as a subject worthy of serious scientific study by many in the United States. Prediction is typically regarded as too "hot to handle" and too controversial. As a student one of us (LRS) was told by a professor in the late 1950s that continental drift was impossible and that serious young scientists should engage in other topics. Similar views are conveyed to many students today regarding earthquake prediction. Scientists working on predictions also must contend with the occupational hazard that many seers and psychics make predictions that are not scientifically based - often very specific, dire predictions. Being more specific and dramatic, they are often given greater emphasis by the mass media than scientifically-based ones. Nevertheless, we think there is room for creative and superior work on the science of earthquakes and on prediction.

Prediction does involve a commitment to monitoring and research on a time scale of decades, a time scale that far exceeds that of typical research grants and contracts in the U.S. Many Japanese scientists seem to take a longer-term view of monitoring and the prospects for prediction. Some who claim that prediction is impossible argue for increased funding for fundamental research, which may represent a nostalgia for the "good old days" when funding for basic research was easier to obtain than in the post cold-war era. Earthquake studies involve a continuum from very basic research to specific societal applications. We see room for excellent work throughout that continuum. Justification of funding for earthquake studies should emphasize the importance of both curiosity-driven research and benefits to society through the reduction of earthquake losses.

A recurrent proposal has been to cease work on prediction and earthquake research and to allocate all funding for earthquakes into better construction of buildings. Infrastructure of a major city, however, is typically built over more than 50 years. While better building codes and their enforcement can be applied to new structures at small additional costs, the greatest threats to life and property are usually associated with a legacy of older structures that were not built to modern standards. Roughly half a trillion dollars would be needed to bring older structures up to present codes in each of the several major U.S. urban areas, an expense that is unlikely to be forthcoming for many of them in the foreseeable future. The capability to make a reliable intermediate-term prediction with say a 5-years time window could provide a rationale for focusing more resources on a major urban area for which such a forecast had been issued. Many older structures could be strengthened on a time scale of a few years. We do note that the City of Los Angeles is making major efforts to strengthen or retire structures that do not meet current codes. Nevertheless, it will take decades to bring the built environment up to certain standards of earthquake resistance even if a given country focuses solely on that topic. We favor balanced national programs that include the science of earthquakes, better delineation of hazards and risks, monitoring, prediction, engineering and mitigation measures of a variety of types. 


\section{Acknowledgements}

We thank K. Jacob, W. Menke and M. Wyss for their critical reading of the manuscript and J. Deng and S. Jaumé for discussions. This work was supported by the Southern California Earthquake Center. SCEC is funded by NSF cooperative agreement EAR-8920136 and USGS cooperative agreement 14-08-001-A0899 and 1434-HQ-97AG01718. Lamont-Doherty Earth Observatory contribution no. 5928; SCEC contribution no. 467.

\section{REFERENCES}

Abercrombie, R. E., Agnew, D. C., and Wyatt, F. K. (1995), Testing a Model of Earthquake Nucleation, Bull. Seismol. Soc. Am. 85, 1873-1878.

Bak, P., TAng, C., and Wiesenfeld, K. (1988), Self-organized Criticality, Phys. Rev. A 38, 364-374. Bakun, W. H., and Lindh, A. G. (1985), The Parkfield, California, Earthquake Prediction Experiment, Science 229, 619-624.

Deng, J., and Sykes, L. R. (1997), Stress Evolution in Southern California, and Triggering of Moderate, Small and Microearthquakes, J. Geophys. Res. 102, 24,411-24,435.

Dieterich, J. H., and Kilgore, B. (1996), Implications of Fault Constitutive Properties for Earthquake Prediction, Proc. Nat. Acad. Sci. USA 93, 3787-3794.

Dodge, D. A., Beroza, G. C., and Ellsworth, W. L. (1996), Detailed Observations of California Foreshock Sequences: Implications for the Earthquake Initiation Process, J. Geophys. Res. 101, 22,371-22,392.

Ellsworth, W. L., Characteristic earthquakes and long-term earthquake forecasts: implications of central California seismicity. In Urban Disaster Mitigation: The Role of Science and Technology (eds. Cheng, F. Y., and Sheu, M. S.) (Elsevier 1995) pp. 1-14.

Evans, R. (1997), Assessment of Schemes for Earthquake Prediction, Geophys. J. Int. 131, 413-420.

Geller, R. S. (1997a), Predicting Earthquakes is Impossible, Los Angeles Times, Feb. 2.

Geller, R. S. (1997b), Earthquakes: Thinking about the Unpredictable, EOS Trans. Amer. Geophys. Union 78, 63-66.

Geller, R. S. (1997c), Predictable Publicity, Seismol. Res. Lett. 68, 477-480.

Geller, R. S. (1997d), Earthquake Prediction: A Critical Review, Geophys. J. Int. 131, 425-450.

Geller, R. S., Jackson, D. D., Kagan, Y. Y., and Mulargia, F. (1997), Earthquakes Cannot be Predicted, Science 275, 1616-1617.

Harris, R. A. (1998a), The Loma Prieta, California, Earthquake of October 17, 1989-Forcasts, U.S. Geol. Survey Prof. Paper 1550-B, 1-28.

HArris, R. A. (1998b), Forecasts of the Loma-Prieta, California, Earthquake, Bull. Seismol. Soc. Am. $88,898-916$.

Jaumé, S. C., and Sykes, L. R. (1996), Evolution of Moderate Seismicity in the San Francisco Bay Region, 1850 to 1993: Seismicity Changes Related of the Occurrence of Large and Great Earthquakes, J. Geophys. Res. 101, 765-789.

Jaumé, S. C., and Sykes, L. R. (1999), Evolving Toward a Critical Point: A Review of Accelerating Seismic Moment/Energy Release prior to Large and Great Earthquakes, Pure appl. geophys, this issue.

Kagan, Y. Y., and JaCKson, D. D. (1991), Long-term Earthquake Clustering, Geophys. J. Int. 104, $117-133$.

Kanamori, H., Hauksson, E., and Heaton, T. (1997), Real-time Seismology and Earthquake Hazard Mitigation, Nature 390, 461-464.

LindH, A. G. (1983), Preliminary Assessment of Long-term Probabilities for Large Earthquakes along Selected Fault Segments of the San Andreas Fault System in California, U.S. Geol. Survey Open-File Rep. 83-63, 1-5.

MaIn, I. (1996), Statistical Physics, Seismogenesis and Seismic Hazard, Rev. Geophys. 34, 433-462. 
MaIN, I. (1997), Long Odds on Prediction, Nature 385, 19-20.

Main, I. G., and Meredith, P. G. (1991), Stress Corrosion Constitutive Laws as a Possible Mechanism of Intermediate-term and Short-term Seismic Quiescence, Geophys. J. Int. 107, 363-372.

Nadeau, R. M., and Johnson, L. R. (1998), Seismological Studies at Parkfield VI: Moment Release Rates and Estimates of Source Parameters for Small Repeating Earthquakes, Bull. Seismol. Soc. Am. $88,790-814$.

Nadeau, R. M., and McEvilly, T. V. (1997), Seismological Studies at Parkfield V: Characteristic Microearthquake Sequences as Fault-zone Drilling Targets, Bull. Seismol. Soc. Am. 87, 1463-1472.

Pacheco, J. F., Scholz, C. H., and Sykes, L. R. (1992), Changes in Frequency-size Relationship from Small to Large Earthquakes, Nature 355, 71-73.

Pepke, S. L., Carlson, J. M., and Shaw, B. E. (1994), Prediction of Large Events on a Dynamical Model of a Fault, J. Geophys. Res. 99, 6769-6788.

ReID, H. F. (1910), The Mechanics of the Earthquake. Vol. 2 of The California Earthquake of April 18, 1906. Report of the State Earthquake Investigation Commission (Carnegie Institution of Washington Publication 87).

Roeloffs, E., and Quilty, E. (1997), Water Level and Strain Changes Preceding and Following the August 4, 1985 Kettleman Hills, California, Earthquake, Pure appl. geophys. 149, 21-60.

Rosendahl, J. M., Vekic, M., and Rutledge, J.E. (1994), Predictability of Large Avalanches on a Sandpile, Phys. Rev. Lett. 73, 537-540.

Scholz, C. H. (1985), The Black Mountain Asperity; Seismic Hazard of the Southern San Francisco Peninsula, California, Geophys. Res. Lett. 12, 717-719.

Scholz, C.H. (1988), Mechanisms of Seismic Quiescences, Pure appl. geophys. 126, 701-718.

Shukla, J. (1998), Predictability in the Midst of Chaos: A Scientific Basis for Climate Forecasting, Science $282,728-731$.

Sykes, L. R. (1996), Intermediate- and Long-term Earthquake Prediction, Proc. Nat. Acad. Sci USA 93, $3732-3739$.

Sykes, L. R., and JaumÉ, S. C. (1990), Seismic Activity on Neighboring Faults as a Long-term Precursor to Large Earthquakes in the San Francisco Bay Area, Nature 348, 595-599.

Sykes, L. R., and Nishenko, S. P. (1984), Probabilities of Occurrence of Large Plate Rupturing Earthquakes for the San Andreas, San Jacinto and Imperial Faults, California, J. Geophys. Res. 89, 5905-5927.

Tanioka, Y., Ruff, L., and Satake, K. (1996), The Sanriku-oki Earthquake of December 28, 1994 (M 7.7): Rupture of a Different Asperity from a Previous Earthquake, Geophys. Res. Lett. 23, 1465-1468.

TrieP, E., and SyKes, L. R. (1997), Frequency of Occurrence of Moderate to Great Earthquakes in Intracontinental Regions, J. Geophys. Res. 102, 9923-9948.

Tsunogai, U., and Wakita, H. (1995), Precursory Chemical Changes in Ground Water: Kobe Earthquake, Japan, Science 269, 61-63.

Tuttle, M. P., and Sykes, L. R. (1992), Re-evaluation of Several Large Historic Earthquakes in the Vicinity of Loma Prieta and Peninsular Segments of the San Andreas Fault, California, Bull Seismol. Soc. Am. 82, 1802-1820.

Wakita, H. (1996), Geochemical Challenge to Earthquake Prediction, Proc. Nat. Acad. Sci USA 93, $3781-3786$.

Wallace, R. E., Davis, J. E., and McNally, K. C. (1984), Terms for Expressing Earthquake Potential, Prediction and Probability, Bull. Seismol. Soc. Am. 74, 1819-1825.

Working Group on California Earthquake Probabilities (1988), Probabilities of Large Earthquakes Occurring in California on the San Andreas Fault, U.S. Geol. Survey Open-File Rep. 88-398, $1-62$.

Wyss, M., Shimazaki, K., and Urabe, T. (1996), Quantitative Mapping of a Precursory Seismic Quiescence to the Izu-Oshima (M 6.5) Earthquake, Japan, Geophys. J. Int. 127, 735-743.

(Received November 12, 1998, revised January 12, 1999, accepted January 22, 1999) 